\title{
Analphoid marker chromosome in a patient with hyper-lgE syndrome, autism, and mild mental retardation
}

Bodo Grimbacher, $M D^{1}$, Amalia S. Dutra, PhD', Steven M. Holland, $M D^{2}$, Roxanne E. Fischer', Maryland Pao, $M D^{3}$, John I. Gallin, $M D^{2}$, and Jennifer M. Puck, $M D^{\prime}$

\begin{abstract}
Hyper-lgE syndrome with recurrent infections (HIES) is a primary immunodeficiency disease characterized by recurrent skin and lung abscesses and extreme elevations of serum IgE, but also involving dentition, bones, and connective tissue. Although the etiology of HIES is unknown, autosomal dominant inheritance has been observed in multiple kindreds. A 17 year old male with sporadic HIES, autism, and mild mental retardation was found to have a supernumerary marker chromosome in peripheral blood lymphocytes and skin fibroblasts. Microdissection and FISH analysis of the marker chromosome showed that it was derived from a small interstitial deletion of one homologue of chromosome 4 q21. Lack of hybridization of probes specific for telomeres and alphoid centromeres, including a centromere 4 specific probe, established that the marker was an analphoid ring chromosome. Comparative genotyping of transformed B-cell subclones with (M+) and without $(\mathrm{M}-)$ the marker chromosome showed loss of the maternal alleles in $\mathrm{M}$ - cells between markers D4S1569 and D4S3010. FISH using YAC clones from 4q21 confirmed the size and location of the interstitial deletion. Thus our patient's phenotypes were associated with de novo formation of a marker chromosome containing $15-20 \mathrm{cM}$ of DNA deleted from his maternally derived chromosome 4. Proximal chromosome $4 \mathrm{q}$ therefore is a candidate region for disease genes for both HIES and autism. Identification of genes disrupted or lost during the formation of the marker chromosome as well as linkage studies in kindreds with HIES or autism may help us to understand the etiology of these complex phenotypes. Genetics in Medicine, 1999:1(5):214-219.
\end{abstract}

Key words: Analphoid, centromere, chromosome 4q21, immunodeficiency, immunoglobulin E, interstitial deletion, Job syndrome, marker ring chromosome

Hyper-IgE syndrome with recurrent infections (HIES) (also called hyper-IgE recurrent infection syndrome and Job syndrome, OMIM \#14,7060, \#24,3700) is a multisystem disorder of unknown etiology affecting the immune system, bones, teeth, and connective tissue. ${ }^{1}$ Although the specific gene defect is unknown, HIES can be inherited as an autosomal dominant trait with variable expressivity. ${ }^{1}$ HIES is characterized by eczema from infancy, recurrent skin abscesses and pneumonia, and extremely elevated levels of serum IgE. ${ }^{1-8}$ Characteristically, bacterial pneumonias in HIES fail to resolve normally and lead to persistent pneumatoceles. By middle adulthood, many patients succumb to complications of chronically superinfected pneumatoceles or progressive loss of lung function.

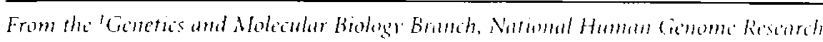

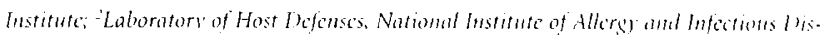

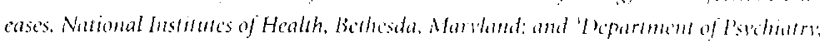
Children's National Medical Centir, Washingten. Ix

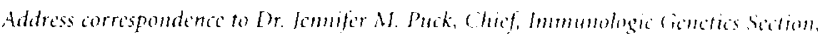

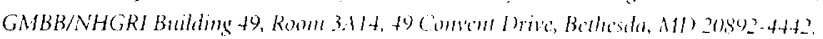
Recoved: April 3. 1999

Accopted: Jome 2: 1999
}

In addition to immunologic defects, distinct nonimmunologic features are associated with HIES, including a characteristic facial appearance, increased nasal width, prominent forehead, high arched palate, retained primary dentition, recurrent bone fractures, scoliosis, craniosynostosis, and hyperextensibility. ${ }^{1,9,10}$ Despite earlier observations of abnormal granulocyte chemotaxis in several HIES patients, no primary underlying immunologic defect has been defined. $4,5,11-1,3$

Since its first descriptions, ${ }^{2-4}$ more than 200 cases of HIES have been published, ${ }^{1,7,14}$ but no associated cytogenetic abnormalities have been found. We screened 52 unrelated HIES probands for cytogenetic anomalies and report here a unique patient with HIES and autism who had an analphoid marker ring chromosome derived from the long arm of chromosome 4.

\section{CASE REPORTS}

The proband, a 17 year old African American male, was born to a 21 year old healthy mother, who has since given birth to two full siblings and two half siblings of the proband, all without medical or cognitive problems. He had neonatal eczema, and subsequently developed multiple facial and scalp abscesses from which Staphylococcus aureus was isolated. His 
total eosinophil count was $4,300 \mathrm{cells} / \mu \mathrm{l}$ (normal $<640$ cells/ $\mu \mathrm{l}$ ) and serum IgE level was 51,670 IU/ml (normal $<130$ $\mathrm{IU} / \mathrm{ml}$ ). At 1.5 years, he experienced his first pneumonia; his sixth and most recent pneumonia at age 16 , caused by $S$. pneumoniat, developed into a pneumatocele. He also suffered from recurrent onychomycosis, chronic sinusitis, and otitis. At 5 years, he fractured the left distal femur while carrying a bag of groceries. The weight of the leg cast induced a second femoral fracture. At age 15 , leg length discrepancy and $10^{\circ}$ of scoliosis were noted. At 8,9 , and 12 years of age, nine primary teeth were extracted to make way for already erupting permanent teeth. At age 17 he still had nine retained primary teeth. Permanent tooth eruption has been delayed for age although tooth number, structure, and maturation were normal.'

The proband's motor, language, social, and developmental milestones were delayed. Testing at ages 8 and 15 showed cognitive and adaptive functioning in the borderline to mild mental retardation range. He has required special education for disabilities in quantitative reasoning, arithmetic, reading, and spelling, but has demonstrated relative strengths in visual detail skills. He has a profound impairment in social interaction, minimal speech, or communication, and restricted patterns of interests consistent with autism.

\section{MATERIALS AND METHODS}

\section{Blood samples and cell lines}

Blood samples from the proband and his mother and a skin biopsy from the proband were obtained for genetic analysis with informed consent under an approved NIH protocol. The father could not be located. An Epstein-Barr virus (EBV) transformed B-cell line was established from the proband. After culture in limiting dilution, subclones of this line were further analyzed.

\section{Cytogenetic analysis}

Karyotyping of high-resolution, G-banded metaphases was performed by standard methods. ${ }^{15.10}$ Microdissection of 16 marker chromosomes was performed. The DNA was amplified with UNI universal primers as described. ${ }^{17}$ For FISH, amplified marker DNA as well as DNA from yeast artificial chromosome (YAC) clones was labeled with SpectrumOrange (Boehringer Mannheim, Mannheim, Germany) using a nick translation kit (Boehringer Mannheim). To each slide was applied $250 \mathrm{ng}$ to $1 \mu \mathrm{g}$ (for PCR product) or $5 \mu \mathrm{g}$ (for YACs) of labeled probe, in which nonunique and nonspecific DNA had been blocked by preannealing with $50 \mu \mathrm{g}$ human Cot-l DNA (Life Technologies, Gaithersburg, MI)). A telomere probe, a chromosome 4 alphoid centromere probe, and an AllHuman-Centromeres probe were used according to manufacturer's instructions (Oncor, Gaithersburg, MD; now Vysis, Downers Grove, IL). YAC clones were selected according to their position on available physical maps [http://www.shgc. stanford.edu/Mapping/phys_map/Chr4YAC.html]. ${ }^{1 \times}$

\section{DNA analysis}

Fluorescent primers for polymorphic markers from the long arm of chromosome 4 were sought from available genetic maps [http://www.marshmed.org/genetics] ${ }^{19}$ and purchased from Research Genetics (Huntsville, AL) and PE/Applied BioSystems (Foster City, CA). Genotyping was performed using conditions appropriate for each primer set. $\mathrm{PCR}$ reactions were analyzed in an ABI 377 sequencer ( $\mathrm{PE} /$ Applied BioSystems). After data assembly with Collection and Analysis software, allele sizes were determined with help of the Genotyper program (all software from PE/Applied BioSystems).

\section{RESULTS}

\section{Cytogenetic studies}

Eight hundred G-banded metaphases from multiple blood samples, including 25 at 850 -band resolution, and 26 metaphases from cultured skin fibroblasts of the proband were analyzed. In both tissues, $75 \%$ of the cells showed a supernumerary marker chromosome (Fig. lA, arrow). Twenty-five percent of the cells appeared to have a normal karyotype (not shown). To address the structure of the marker chromosome, staining with a telomere probe was performed. In 20 metaphases, the marker was the only chromosome lacking telomeric repeat signals (Fig. $1 \mathrm{~B}$ ), consistent with a ring chromosome derived from an interstitial deletion. In addition, the marker was directly observed to have a ring structure in a prometaphase spread (Fig. $1 \mathrm{C}$, arrow). To investigate the origin of the marker chromosome, it was microdissected, amplified by PCR, labeled, and used for FISH analysis. On control metaphases, the marker probe stained only a single region, chromosome $4 \mathrm{q} 21$, on both homologues (not shown). In the proband's cells that contained the marker chromosome, the probe stained only the marker plus one homologue of chromosome 4q21 (Fig. 1, C and D). The second homologue of chromosome 4 had no detectable staining. In the $25 \%$ of cells that were marker negative, again only one of the two chromosome 4 homologues stained (not shown). Thus, the marker represented material deleted from one copy of chromosome $4 \mathrm{q} 21$. All of the patient's somatic cells were therefore abnormal, $75 \%$ with a marker ring derived from $4 \mathrm{q} 21$, and $25 \%$ that had lost the ring and were thus deleted for one copy of $4 \mathrm{q} 21$ chromosomal material. In order to be distributed to daughter cells during mitosis, the marker chromosome must have contained a region with centromeric function. Centromeres are generally identified by the presence of repetitive DNA sequences known as alpha satellite, or alphoid, sequences. However, probes representing alphoid sequences from all of the human chromosomes, including a chromosome 4 specific alphoid centromere probe, failed to show detectable hybridization to the marker chromosome (Fig. $1 \mathrm{D}$ and data not shown). An unidentified nonalphoid, or analphoid, repeat sequence or a low copy number of alphoid repeats functioning as a neo-centromere could have escaped detection. 

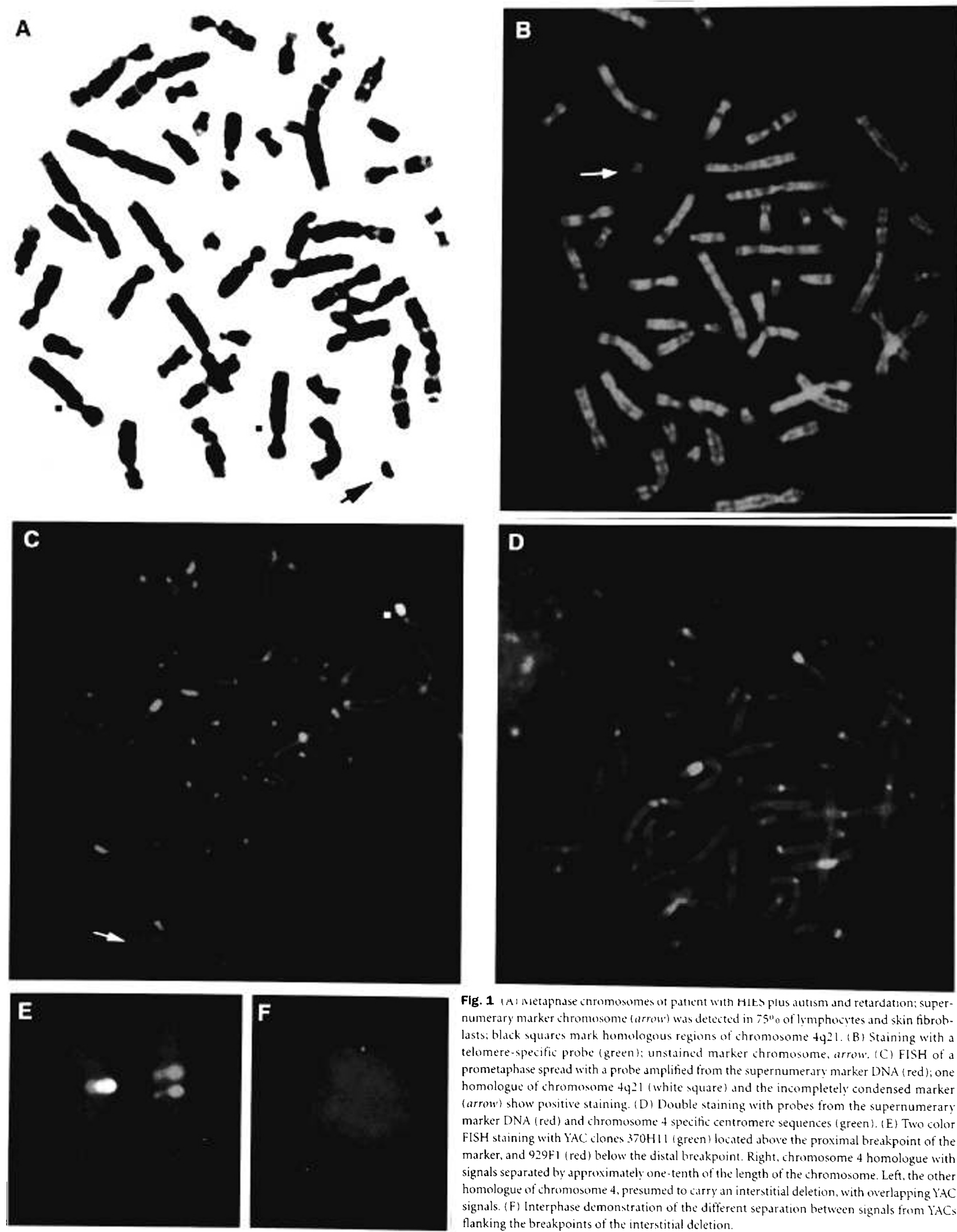

Fig. 1 i M s metapnase cnromosomes of patient with Hits plus autism and retardation; supernumerary marker chromosome (arrow) was detected in $75^{\circ} 0$ of lymphecites and skin fibrohlasts: black squares mark homologous regions of chromosome ty21. (B) Staining with a telomere-specific probe (green); unstained marker ihromosome, arrow. (C) FISH of a prometaphase spread with a probe amplified from the supernumerary marker DNA (red); one homologue of chromosome $4 y_{2} 1$ ( white square) and the incompletely condensed marker (arrow) show positive staining. (D) Double staining with probes from the supernumerary marker DNA (red) and chromosome 4 specific centromere sequences (green). (E) Two color FISH staining with YAC clones $370 \mathrm{HI} I$ (green) located above the proximal breakpoint of the marker, and 929F1 (red) below the distal breakpoint. Right, chromosome 4 homologue with signals separated by approximately one-tenth of the length of the chromosome. Left, the other homologue of chromosome 4 , presumed to carry an interstitial deletion, with overlapping YAC signals. (F) Interphase demonstration of the different separation between signals from litCs flanking the breakpoints of the interstitial deletion. 


\section{Molecular DNA studies}

Subclones from limiting dilution of the EBV transformed cell line from the proband were analyzed by FISH to identify those that had retained $(\mathrm{M}+)$ or lost $(\mathrm{M}-)$ the marker chromosome. DNA samples prepared from the proband's $M+$ and $\mathrm{M}$ - subcloned cell lines were compared with genomic DNA from whole blood from his mother. Seventeen polymorphic markers on chromosome 4 between D4S2629 and D4S423 were heterozygous in proband $\mathrm{M}+\mathrm{DNA}$. In contrast, $\mathrm{M}-\mathrm{DNA}$ was hemizygous for the markers D4S398, D4S392, and D4S2963 on chromosome 4q21, but heterozygous for the more centromeric markers D4\$2629 and D4S1596, as well as the more telomeric markers D4S3010 and D4S423 (Fig. 2). Thus the upper breakpoint of the marker region was between D4S1569 at $71.8 \mathrm{cM}$ and D4S398 at $72.5 \mathrm{cM}$, and the lower breakpoint was between D4S2963 at $87 \mathrm{cM}$ and D4S3010 at $90.3 \mathrm{cM}$ from the top of chromosome $4 .{ }^{19}$ These data were consistent with the hypothesis that the marker was a chromosomal segment derived from a $15-20 \mathrm{cM}$ region of $4 \mathrm{q} 21$. Maternal genomic DNA was analyzed at the same polymorphic loci for comparison with the proband's genotype. As shown in Figure 2, at D4S398, D4S392, and D4S2963, which gave hemizygous signals in the proband's $\mathrm{M}-\mathrm{DNA}$, the alleles that were retained were not carried by the mother, indicating that the maternally inherited chromosome 4 was the one that had undergone deletion and marker formation in the proband.

\section{FISH studies with YAC clones}

DNA from yeast clones containing YACs from proximal chromosome $4 \mathrm{q}^{18}$ were labeled and used for FISH on metaphases from the proband. YAC clones $822 \mathrm{Dl} 10,256 \mathrm{Al} 10,826 \mathrm{~F} 5$, and $370 \mathrm{H} 11$, located proximal to D4S1569 stained both homologues of chromosome 4. YAC clones $898 \mathrm{H} 4$ and $915 \mathrm{Bl}$, located distal to D4S398, stained the marker chromosome and only one homologue of chromosome 4 (not shown). Therefore, the latter two YACs contain DNA involved in the interstitial dele- tion that gave rise to the marker chromosome. YAC clone 929F1, located distal to D4S3010, again stained both copies of chromosome 4 but did not stain the marker chromosome. To estimate the physical size of the deleted DNA fragment, two color FISH was performed using YAC clone $370 \mathrm{H} 11$ proximal to the interstitial deletion and YAC clone 929F1 distal to the interstitial deletion. In one homologue, the two signals were separated by approximately $10 \%$ of the length of the chromosome, whereas the other homologue demonstrated overlapping signals (Fig. 1E). Similarly, interphase signals consistently showed different distances separating the signal pairs (Fig. IF). In metaphases from healthy controls, these YAC markers were equally separated on both chromatids, supporting the hypothesis of interstitial deletion coincident with the formation of the marker chromosome in the proband.

\section{DISCUSSION}

Patients with any syndrome plus additional findings, particularly cognitive impairment, may be suspected to have cytogenetic abnormalities. Our proband was unique in that he had sporadic, typical HIES, but also had intellectual impairment with autistic features, not part of the HIES phenotype either in our 44 patient $\mathrm{NIH}$ cohort ${ }^{1}$ or in $>200$ cases reviewed in the literature. ${ }^{6-8,14}$ However, in view of the cytogenetic abnormality in our patient, it may be possible to link the immunologic and cognitive phenotypes to a genomic location. During the marker chromosome formation, loci might have been lost or disrupted, leading to the HIES and autism phenotypes.

The underlying causes of HIES and of autism could be single gene defects or contiguous gene deletion or dysregulation syndromes. Therefore, $4 \mathrm{q}$ should be considered a candidate region for linkage studies of HIES and autism. Our preliminary linkage analysis in familial HIES has demonstrated a multipoint LOD score of 3.69 for linkage of HIES to markers on proximal $4 \mathrm{q} .{ }^{20}$ In addition, a recent genome wide linkage scan for familial autism revealed multiple markers with positive
D453000
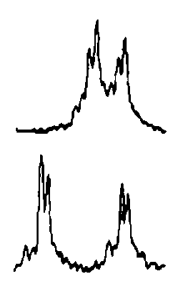

Patient (M+)

Patient (M-)

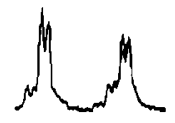

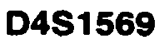
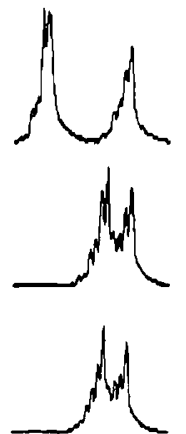

D45398
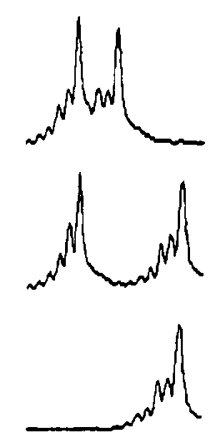

D45392

D4S2963

D4S3010
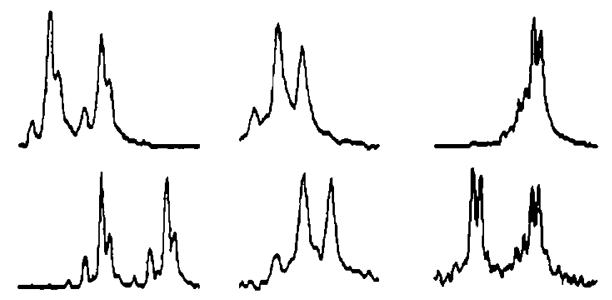<smiles>CC1CCC(C)C(C)N1</smiles>
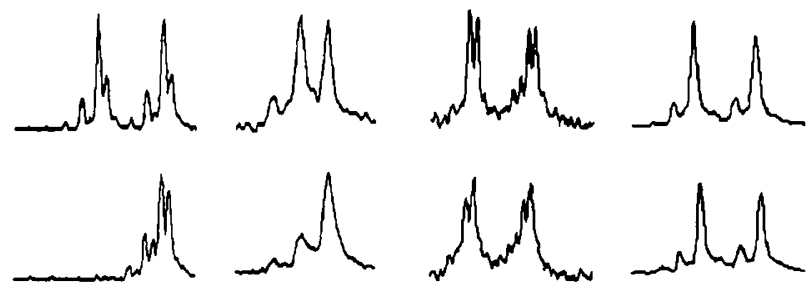

Fig. 2 Comparative genotyping of DNA from mother and from patient lymphocyte clones with marker (M+) and without marker (M-). Polymorphic markers D4S398, D4S392, and D4S2963 were hemizygous in M- subclone; retained allele wis not the maternally inherited allele. Marker order from centromeric (left) to telomeric (right). 
LOD scores on $4 \mathrm{q}$ including markers located on our proband's marker chromosome region; however, significant linkage with a $p$ value of 0.0199 was achieved only with marker D4S1535 on $4 \mathrm{q} 35 .{ }^{21}$

Our proband's marker chromosome was derived from an interstitial deletion of chromosome $4 \mathrm{q} 21$. Genotyping of polymorphic markers in $\mathrm{M}+$ and $\mathrm{M}-\mathrm{B}$-cell subclones revealed that the marker formation was a de novo event involving breakpoints between D4S1569 and D4S398 proximally and D4S2963 and D4S3010 distally on the maternally derived chromosome 4. According to available maps, ${ }^{14}$ D4S398 and D4S2963 are 14.5 CM, and D4S1569 and D4S3010 are $18.5 \mathrm{cM}$ apart. Two color FISH staining with YACs derived from above and below the breakpoints ${ }^{18}$ demonstrated an interstitial deletion of approximately $10 \%$ of the length of the chromosome. Chromosome 4 is estimated to have a genetic distance of $211 \mathrm{cM} .{ }^{19}$ Thus deletion of the size observed would be equivalent to approximately $20 \mathrm{cM}$. This value is in close agreement with the mapped genetic distances of the markers involved in the loss of heterozygosity.

Marker chromosomes have been found in approximately 1 in 2,500 amniocenteses and 1 in 10,000 living individuals, sometimes inherited from healthy parents. ${ }^{22}$ Most contain duplicated chromosomal material including alphoid repeats associated with centromeres, and even the unusual analphoid markers are often composed of inverted duplications. ${ }^{23}$ Mental retardation, the most common phenotype associated with de novo marker chromosomes, is thus generally attributed to partial trisomy. There have been five reported cases of marker chromosomes derived from proximal chromosome $4 q, 24-27$ all of them larger than our proband's, more proximally located, and containing alphoid repeat sequences specific for the chromosome 4 centromere. Clinically, these ring formations were associated with severe embryopathy with alobar holoprosencephaly in one case; ${ }^{26}$ mental retardation with moderate dysmorphology in two cases, ${ }^{24,27}$ and a normal phenotype in one case. ${ }^{25}$

In contrast to the above cases, we could not detect alphoid sequences by FISH in the marker in our proband, and we do not know if it contains duplicated DNA. However, $25 \%$ of our proband's lymphocytes and fibroblasts lacked the marker, probably due to somatic mitotic nondysjunction, and were thus monosomic for $4 \mathrm{q} 21$. In this regard, reported interstitial deletions might shed light on the expected phenotype of the partial $4 \mathrm{q}$ monosomy of our proband. There are more than 20 published cases with interstitial deletions involving $4 \mathrm{q} 11$ to $4 \mathrm{q} 21.1 .^{28-48}$ Taken together, these reports suggest that deletions involving only $4 q 11-22$ were compatible with life, whereas larger deletions involving $4 \mathrm{q} 13.2$ to $4 \mathrm{q} 23$ produced severe abnormalities with fetal or infantile demise. The smaller deletions, reported in patients between 7 months and 17 years of age, were all associated with facial anomalies and, in all but one patient, ${ }^{46}$ severe mental retardation was observed. The autosomal dominant Piebald trait, due to mutations in the c-kit proto-oncogene in $4 \mathrm{q} 12,{ }^{49-51}$ occurred in the cases in which this locus was deleted. Other than retardation, the phenotypes of previously reported patients with small $4 \mathrm{q}$ deletions did not resemble that of our patient; the reported facial anomalies were not characteristic of HIES, and neither autism nor immunologic abnormalities suggestive of HIES were noted.

Given that HIES can be inherited as an autosomal dominant trait, pathologic mechanisms for HIES in our patient include: (a) haploinsufficiency due to disruption of gene(s) at the upper or lower boundaries of the deletion; (b) alteration of a gene by truncation or fusion with another gene, resulting in production of a toxic protein with a dominant negative effect; (c) haploinsufficiency due to loss of genetic material, so far undetected, at the marker breakpoints or elsewhere if the marker formation was a complex event involving multiple DNA breaks and rejoinings; (d) altered expression of gene(s) on the marker or nearby on $4 \mathrm{q} 21$ due to disruption of a locus control region or imprinted region. The lack of a HIES phenotype in other published cases with $4 \mathrm{q}$ deletions argues against the hypothesis of haploinsufficiency causing HIES. However, the partial monosomy of cells that have lost the marker ring may contribute to the cognitive aspects of our patient's phenotype.

This case illustrates the benefit of cytogenetic analysis in a unique patient with a defined syndrome plus an additional phenotype. The pursuit of transcripts within the region of the proband's marker chromosome, and particularly at the marker breakpoints, may help to identify a disease gene for HIES.

\section{Acknowledgments}

The authors thank Michael Bittner and Yuan Jiang for assistance with microdissection, Evgenia Pak for assistance with FISH, Anne O'Connell for dental evaluation, Maximilian Muenke for helpful discussions, and the patient and his mother for their participation. B.G. was supported by Deutsche Forschungsgemeinschaft, Grant No. GR1617/1-1 and the Immune Deficiency Foundation.

\section{References}

1. Grimbacher B, Holland SM. Gallin II, Greenberg F, Hill SC, Malech HL, Miller IA, O'Connell AC, Puck IM. Hyper-IgE syndrome: An autosomal dominant multisystem disorder. N Engl I Med 1999:340:692-702.

2. Davis SD, Schaller I, Wedgwood RI. Job's syndrome: Recurrent, "cold," staphylococcal abscesses. Lanct 1966;1:1013-1015.

3. Buckley RH, Wray BB, Belmaker EZ. Extreme hyperimmunoglobulin $\mathrm{E}$ and undue susceptibility to infection. Pediatrics 19:3:49:59-70.

4. Hill HR, Quie PG. Raised serum lgE levels and defective neutrophil chemotaxis in three children with eczema and recurrent bacterial infections. Lancet 1974:1:183-187.

5. Hill HR, Ochs HD, Quie PG, Clark RA, Pabst HF, Klebanoff SI, Wedgwood RI. Defect in neutrophil granulocite chemotaxis in Job's syndrome of recurrent "cold" staphylococial abscesses. Lamiot 1974:2:617-619.

6. Donabedian H, Gallin II. The hyperimmunoglobulin E recurrent infection (Job's) syndrome. A review of the NIH experience and the literature. Medicine 1983:62:195-208.

7. Buckley RH. Disorders of the $\lg E$ system: The hyper $\operatorname{lgE}$ syndrome. In: Stiehm ER, editor. Immunologic disorders in infants and children. 4th edition. Philadelphia: W.B. Saunders, 1996:413-422.

8. Holland SM, Gallin JI. Disorders of granulocytes and monocytes, Chapter 62. In: Fauci A, Braunwald E, lsselbacher K, Wilson ID, Martin JB, Kasper DL, Hauser SL, Longo DL, editors. Harrison's principles of internal medicine. 14th edition. New York: McGraw-Hill, 1998:351-356.

9. Cohen MM. Craniosynostosis update 1987. Am J Med Genet 1988;4(Suppl):99-148.

10. Borges WG, Hensley T, Carey IC, Petrak BA. Hill HR. The face of Job. I Pidiat 1981;33:303-305. 


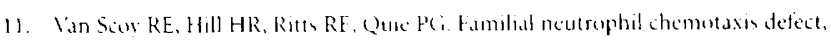
recurent backerial infections, mucocutancous candidiasis, and hyperim-

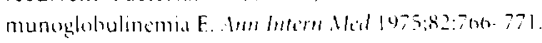

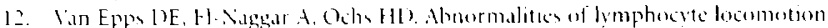

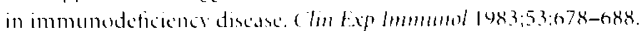

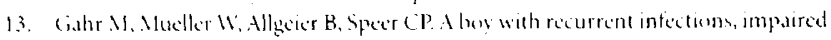

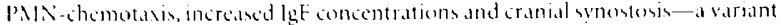
of the heper-lge syndreme? Hele Fediatr tita 1487:42:185-190.

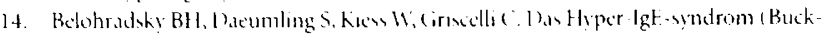
lev-oder Hiob-Svondroml. In: Frgebnisse der Inneren Medizin und Kinderheilkunde, Berlin: Springer Verlag. 145:-1-30

15. Sestright $\mathrm{Ml}$. High resolution studies an the pattern of induced exchanges in the

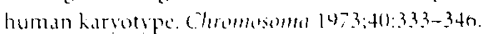

16. Dutra AS, Mignen E. Puck MI. (iche localization and syntenic mapping by FISH

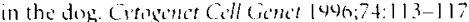

1-. Meltzer PS Guan XY. Burgess A. Trene M. Rapid generation of region specific probes be chromosome microdissection and their application. Nat cienet $1992: 1: 24-28$

18. Stewart FA, Mckusick KB, Agganwal A, Baiorek E. Brady S, Chu A, Fang N, Hadley [), Harris . I, Hussain S, Lee R, Maratukulam A, ()' (nnnor K, Perkins S, Piercy M, Qin F. Reif T. Sanders C. She X, Sun WI., Tabar P, Voytichy S. Cowles S. Fan JB, Wader C. (Quackenbush J. MVers R.M. Cox DR. An STS-based radiation hybrid map of the human genome. (inomic Res 1997;7:422-433.

19. Broman KW: Mlurray IC. Sheffield V': White RL, Weber Il. Comprehensive human genetic maps: Individual and sex-specific variation in recombination. Am / Hum (ienct 1948:03:801-869.

20. Grimbacher B, Dutra AS, Holland SN, Schaffer AA, Greenterg F, Malech H, Gallin II. Puck JMI. Hyper IgE recurrent infection syndrome: Extended phenotype, a cytogenetic anomaly and linkage to tq (Abstract). Am / Hum Genet 1998;63 (Suppl):A767.

21. Philippe A, Martinez M, Ciuilloud-Bataille M, Gillherg C, Rastam M. Sponheim E, Coleman . I, Zappeila M, Aschauer H, van Malldergerme L, Penet C. Feingold I. Brice A, Lebover .M. Genome-wide scan for autism susceptibility genes. Hum Mol Genet 1999;8:805-812

22. Warburton D. De novo balanced chromosome rearrangements and extra marker chromosomes identified at prenatal diagnosis: Clinical significance and distribution of breakpoints. Am / Hum Gent 1991:49:995-1013.

23. Choo KHA. Chromatin dinamics '97. Centromere DNA drnamics: Latent centromeres and neocentromere formation. Am J Hum Genet 1997;61:1225-1233.

It Callen DF. EyTe H. Yip II), Freemuntle J. Haan EA. Molecular ortogenetic and clinical studies of 42 patients with marker chromosomes. Am J Meal Genet 1992;43:709-715.

25. Crolla IA, Dennis NR, Jacobs PA. A non-isotypic in situ hybridization study of the chromosomal origin of 15 supernumerary marker chromosomes in man. I Med Genet 1992;29:699-703.

26. Blennow E, Anneren G. Bui TH. Beggren E, Asadi E, Nordenskioeld M. Charac terization of supernumerary marker chromosomes by fluorescence in situ hybridization (FISH). Am / Hum Gonet 1993:53:433-442.

2- Fang YT. Evre HI, Bohlander SK. Estop A. MkPherson E, Traeger T, Riess O, Callen DF. Mechanisms of small marker formation suggested by the molecular characterization of two small accessory marker chromosomes derived from chromosome 4. Am J Hum Ginet 1995;57:1137-1142.

28. Funderburk SI, Crandall BF. Dominant Piebald trait in a retarded child with a reciprocal translocation and small intercalary deletion. Am / Hum (ienct 1974:26:715-722

29. Lacassie Y. Thurmon TF, Tracy MC, Pelias M.IZ. Pichald trait in a retarded child with interstitial deletion of chromosome 4. Am / Hum Gine' 1977:29:641-642.

30. Mikkelsen M, Jacobsen P. Henningsen K. Possible localization of Gi-system on chromosome 4. Loss of long arm 4 matcrial associated with father-child incom. patibility within the Gi-system. Hum Hered 1977;27:105-107.

31. Loughman WD, Mitchell IA, Packman S, Grizzard S, McWhinney A. Interstitia deletion of $4 \mathrm{q}(46, X X$,del $(4)(\mathrm{q} 21,3: 26 \%)$ in an infant with congenital anomalies. Am / Hum Ginet 1974;31:77A.

32. MiDermott A. Cain R. Howell R. Partial monosomy of long arm of chromosome 4 due to interstitial deletion. Hum Genet 1980;53:305-307.

33. Mitchcll JA, Packman S, Loughman WD, Fineman RM, Zackai E, Patil SR, Emanue $B$, Bartley IA, Hanson I $W$ '. Deletions of different segments of the long arm of chromoseme 4. Am / Med Genet 1981;8:73-89.

34. Lech H, Kubsiska I, Wisniewski !. The child with congenital anomalies and interstitial deletion of the long arm of chromosome 4. KTin Padiatr 1982;194:117-119.

35. Camphill IM, Williams I, Batcup G. Interstitial deletion of chromosome 4q diag nosed prenatally. / Med (jenet 1986;23:366-368.

3h. Beall $\mathrm{MH}$, Falk RE, Ying KL. A patient with interstitial deletion of the proximal portion of the long arm of chromosome 4. Am J Med Genet 1988;31:553-557.

37. Hoo II. Haslam RH, VanOrman C. Tentative assignment of piebald trait to chromosome band tq12. Hum Genet 1988;73:230-231

38. Fagan K, Gill A. A new interstitial deletion of $4 \mathrm{q}$ (q21.1::q22.1). J Med Gener 1989:26:644-6.47

39. Mascari MI, Mowrey PN, Ramer IC, Ladda RL. Severe mental retardation and mild dy'smorphism: Association with an uncommon interstitial deletion of chromosome 4. Clin Cytogenet 1989:A821 Supp 11:316

40. Yamamoto $\mathrm{Y}$ ' Nishimoto $\mathrm{H}$, Ikemoto S. Interstitial deletion of the proximal long arm of chromosome 4 associated with father-child incompatibility within the Gcsystem: Probable reduced gene dosage effect and partial piebald trait. Am J Med Genet 1989:32:520-523

41. Curtis MA, Quarrell OW, Cobon AM, Cummins M. Interstitial deletion of chromosome 4, del(4)(q12q21.1), in a child with congenital abnormalities. J Med Genet 1990;27:64-66.

42. Rose NC, Schneider A, McDonald-McGinn DM, Caserta C, Emanuel BS, Zackai EH. Interstitial deletion of $4\left(\mathrm{q}_{2} \mathrm{lq} 25\right)$ in a liveborn male. Am J Med Genet 1991;40:77-79.

43. Sijmons RH, Kristoffersson U, Tuerlings JH, Ljung R, Dijkhuis-Stoffelsma R, Breed AS. Piebaldism in a mentally retarded girl with rare deletion of the long arm of chromosome 4. Pediatr Dermatol 1993;10:235-239.

44. Kulharya AS, Maberry M, Kukolich MK, Day DW, Schneider NR, Wilson GN, Tonk $\mathrm{V}$. Interstitial deletions 4q21.1q25 and 4q25q27: Phenotypic variability and relation to Rieger anomaly. Am JMed Genet 1995;55:165-170.

45. Nowaczyk MII. Teshima IE, Siegel-Bartelt J, Clarke JT. Deletion 4q21/4q22 syndrome: Two patients with de novo $4 \mathrm{q} 21.3 \mathrm{q} 23$ and $4 \mathrm{q} 13.2 \mathrm{q} 23$ deletions. Am J Med Genet 1997;69:400-405

46. Sthinzel A, Braegger CP, Brecevic L, Dutly F, Binkert F. Interstitial deletion, del(4)(q12q21.1), owing to de novo unbalanced translocation in a 2 year old girl: Further evidence that the Piebald trait maps to proximal 4q12.J Med Genet 1997:34:692-695.

47. Slavotinek A, Kingston $\mathrm{H}$. Interstitial deletion of bands 4q12-q13.1: Case report and review of proximal 4q deletions. J Med Genet 1997;34:862-865.

48. Fuijmoto A. Reddy KS. Spinks R. Interstitial deletion of chromosome 4, del( 4$)(q 1$ - 221.1$)$, in a mentally retarded boy with a Piebald trait, due to maternal insertion, ins $(8 ; 4)$. Am J Med Genet 1998;75:78-81.

49. Fleischman RA. Human Piebald trait resulting from a dominant negative mutant allele of the $\mathrm{c}$-kit membrane receptor gene. J Clin Invest 1992;89:1713-1717.

50. Spritz RA, Droetto S, Fukushima Y. Deletion of the KIT and PDGFRA genes in a patient with piebaldism. Am J Met Genet 1992;44:492-495.

51. Spritz RA, Giebel LB, Holmes SA. Dominant negative and loss of function mutations of the $\mathrm{c}$-kit (mast/stem cell growth factor receptor) proto-oncogene in human piebaldism. Am I Hum Genet 1992b;50:261-269. 